\title{
The Journal of Undergraduate Research
}

Volume 12 Journal of Undergraduate Research,

Volume 12: 2014

Article 4

2014

\section{Integration of a Pulsating Heat Pipe in a Flat Plate Heat Sink}

Mitchell Hoesing

South Dakota State University

Follow this and additional works at: http://openprairie.sdstate.edu/jur

Part of the Mechanical Engineering Commons

\section{Recommended Citation}

Hoesing, Mitchell (2014) "Integration of a Pulsating Heat Pipe in a Flat Plate Heat Sink," The Journal of Undergraduate Research: Vol. 12, Article 4.

Available at: http://openprairie.sdstate.edu/jur/vol12/iss1/4

This Article is brought to you for free and open access by Open PRAIRIE: Open Public Research Access Institutional Repository and Information Exchange. It has been accepted for inclusion in The Journal of Undergraduate Research by an authorized administrator of Open PRAIRIE: Open Public Research Access Institutional Repository and Information Exchange. For more information, please contact michael.biondo@sdstate.edu. 


\title{
Integration of a Pulsating Heat Pipe in a Flat Plate Heat Sink
}

\author{
Author: \\ Mitchell Hoesing \\ Faculty Sponsor: \\ Dr. Gregory Michna \\ Department: \\ Mechanical Engineering

\section{ABSTRACT}

The ongoing development of faster and smaller electronic components has led to a need for new technologies to effectively dissipate waste thermal energy. The pulsating heat pipe (PHP) shows potential to meet this need, due to its high heat flux capacity, simplicity, and low cost. A flat plate PHP was integrated into an aluminum flat plate heat sink with a simulated electronic load. The PHP heat sink used water as the working fluid and had 20 parallel channels with dimensions $2 \mathrm{~mm} \times 2 \mathrm{~mm} \times 119 \mathrm{~mm}$. Experiments were run under various operating conditions, and the thermal resistance of the PHP was calculated. The performance enhancement provided by the PHP was assessed by comparing the thermal resistance of the heat sink with no working fluid to that of it charged with water.

Uncharged, the PHP was found to have a resistance of $1.97 \mathrm{~K} / \mathrm{W}$. Charged to a fill ratio of approximately $75 \%$ and oriented vertically, the PHP achieved a resistance of $0.49 \mathrm{~K} / \mathrm{W}$ and $0.53 \mathrm{~K} / \mathrm{W}$ when the condenser temperature was set to $20^{\circ} \mathrm{C}$ and $30^{\circ} \mathrm{C}$, respectively. When the PHP was tilted to $45^{\circ}$ above horizontal, the PHP had a resistance of $0.76 \mathrm{~K} / \mathrm{W}$ and .59 $\mathrm{K} / \mathrm{W}$ when the condenser was set $20^{\circ} \mathrm{C}$ and $30^{\circ} \mathrm{C}$, respectively. The PHP greatly improves the heat transfer properties of the heat sink compared to the aluminum plate alone. Additional considerations regarding flat plate PHP design are also presented.

\section{INTRODUCTION}

The miniaturization and improvement of performance of electronics has led to thermal management becoming a limiting factor in their development. This has created a need for 
devices that can effectively dissipate very high heat fluxes and maintain acceptable electronic temperatures [1]. For many microprocessors, the hottest allowable operating temperature is approximately $90^{\circ} \mathrm{C}$. If this temperature is exceeded, the microprocessor's performance and lifetime are negatively impacted. One device with the potential to meet this growing thermal management need is the pulsating heat pipe (PHP), also known as the oscillating heat pipe.

First proposed by Akachi et al. [2, 3], PHPs are simple, two-phase heat transfer devices. Unlike traditional heat pipes, PHPs do not require a wicking system, have a wider range of form factors, are easier to manufacturer, and have fewer operating limits such as temperature range and heat transfer rate. Due to the simplicity of PHPs, they also offer a significant weight reduction, making them ideal for aerospace applications [4].

A PHP can be divided into three main regions: the evaporator, condenser, and adiabatic sections, which are connected by meandering mini-channels (Fig. 1). A two-phase working fluid acts as the heat transfer medium. When the PHP is operating, the working fluid is in a two-phase state consisting of liquid slugs and vapor bubbles. Unstable pressure differentials between the evaporator and condenser sections generate the pulsating motion. The pressure differentials are due to temperature differences between the evaporator and condenser sections. Unlike thermosyphons, PHPs are not highly dependent on gravity [5]. This indicates that PHPs will function in multiple orientations and in micro-gravity environments $[6,7]$. 


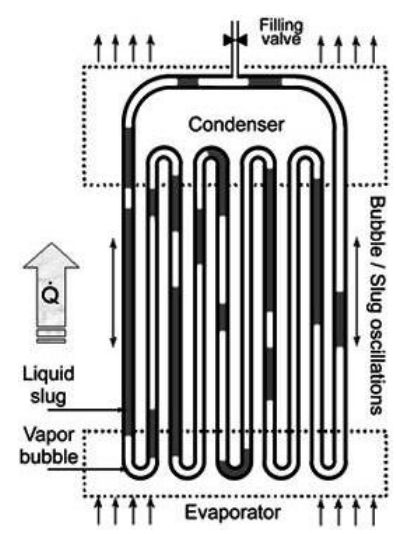

Figure 2: Pulsating heat pipe primary components [5], consisting of an evaporator, condenser, and adiabatic section.

Fluid fill ratio, orientation, geometric parameters, and heat input affect the performance of a PHP. A PHP has an optimum fill ratio, the volume of liquid in the PHP compared to the total volume of the channels, generally between $25 \%-75 \%$ [8-10]. Fill ratios outside of this range tend to limit oscillation, reducing heat transfer.

When water is used as the working fluid, the acceptable channel dimensions are limited to the mini channel scale for proper operation, other fluids, such as, refrigerants may operate in the micro channel scale. The channels must be sized appropriately, so the working fluid can create vapor bubbles due to surface tension. Since fluid surface tension is the main driver of channel size, the Bond number (Eq. 1) is often used to give the range of possible channel diameters for PHP operation.

$$
B o=\frac{D^{2} g\left(\rho_{l}-\rho_{v}\right)}{\sigma}
$$

It has been shown that there exists an upper Bond number limit for operation, between 3.39 and 4. Similarly, a lower limit exists between 0.36 and 0.49 [6]. If the hydraulic diameter is sized outside this range, the working fluid will be unable to form vapor bubbles and pulsate. 
Studies by Yang et al. [11] and Khandekar et al. [12] indicate that thermal resistance can be reduced when square channels have low fill rates and are vertically heated. This is due to the sharp edges of the channels acting as a capillary structure, effectively creating a gravityassisted thermosyphon. PHPs with high fill ratios and/or circular channels will not see this effect.

Heat input also affects performance. Various analyses of PHP performance indicate that as heat input is increased, the thermal resistance decreases $[9,13,14]$. It has been shown the heat removal rate of the cooling mechanism, i.e. cooling bath or air stream, limits the minimum thermal resistance that can be achieved by the PHP [15].

Flat plate PHPs have been investigated by Khandekar et al. [5]. Transverse heating can be a significant factor in PHP operation. In their study, a flat plate PHP was constructed. It had $2.2 \mathrm{~mm} \times 2.0 \mathrm{~mm}$ channels that contained $0.5 \mathrm{~mm}$ of aluminum separating each channel. As a result, two adjacent channels with temperature gradients would quickly equalize. This also causes pressure gradients to equalize, mitigating pulsation and heat transfer. It was recommended that heat transfer between channels be reduced to improve performance.

To help improve current PHP performance, innovative design features have been implemented; one example is from Thompson et al. [4]. Such design features utilize a Tesla type check valve to regulate the direction of the fluid flow of the PHP. By promoting fluid flow in one direction, pulsations would be less chaotic. As a result, performance was improved when compared to a PHP without the check valve.

Another design innovation by Thompson et al. [16] was to produce a 3-D PHP. The channel density was much higher than that on typical flat plate PHPs. As a result of the high channel density, the PHP was capable of transferring heat fluxes up to $300 \mathrm{~W} / \mathrm{cm}^{2}$. Design innovations such as these should help to improve PHP performance to make it viable option for thermal management needs.

In this study, a flat plate PHP was developed to meet the cooling needs of small, high heat flux electronics devices and to investigate the operational characteristics of PHPs. 
Performance of the PHP will be compared to similar PHPs studied to identify possible improvements for future iterations. This will be done to develop innovative design solutions that may be implemented to enhance the heat transfer capacity of the PHP.

\section{APPARATUS AND METHODS}

\section{Apparatus}

The PHP apparatus used in this investigation (Fig. 2) consisted of a milled aluminum plate, clear polycarbonate cover, rubber o-ring, and structure for varying the inclination angle. The milled aluminum block ( $177 \mathrm{~mm} \times 127 \mathrm{~mm} \times 3.75 \mathrm{~mm}$ ) has channels that are $2 \mathrm{~mm} \times$ $2 \mathrm{~mm} \times 119 \mathrm{~mm}$ with $2 \mathrm{~mm}$ of material between each channel. There were 20 channels and 10 turns each in the evaporator and condenser sections, which created a closed-loop PHP. A charging port was machined into one side of the aluminum block. A $6.35-\mathrm{mm}$ transparent polycarbonate plate covered the channels to allow for visualization of the fluid flow. An EPDM o-ring and fasteners created a seal between the aluminum block and polycarbonate cover. The PHP was charged with water that resulted in a Bond number of 0.528 , within the operational range determined by previous work.

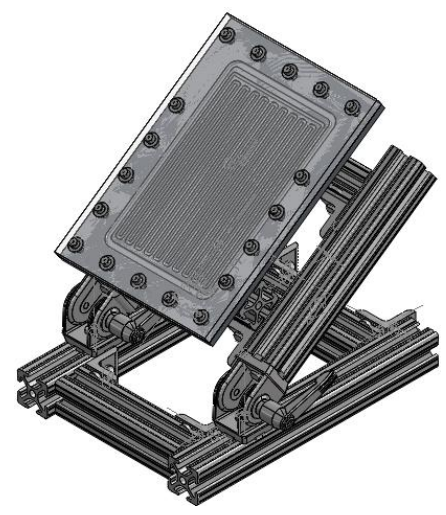

Figure 3: 3-D model of the pulsating heat pipe apparatus.

A heating block was constructed and placed in contact with the backside of the evaporator section of the PHP heat sink (Fig. 3). The heating block consisted of a copper block (83 
mm x $32 \mathrm{~mm}$ x $9.5 \mathrm{~mm}$ ) with four embedded $100 \mathrm{~W}$ cartridge heaters. A 120 VAC variable output transformer was used to control the power supplied to the cartridge heaters. A cooling block was constructed and clamped to the backside of the condenser section of the PHP heat sink. The cooling block consisted of an aluminum block (82.5 $\mathrm{mm}$ x 31.75 $\mathrm{mm} \times 31.75 \mathrm{~mm}$ ). A 50/50 volume percent water/antifreeze solution flowed through the cooling block, removing heat from the PHP. A thermostatic chiller circulated and regulated the temperature of the solution. High-density fiberglass insulation, $2.54 \mathrm{~cm}$ thick, surrounded the heating and cooling blocks, as well as the front and back of the PHP heat sink.

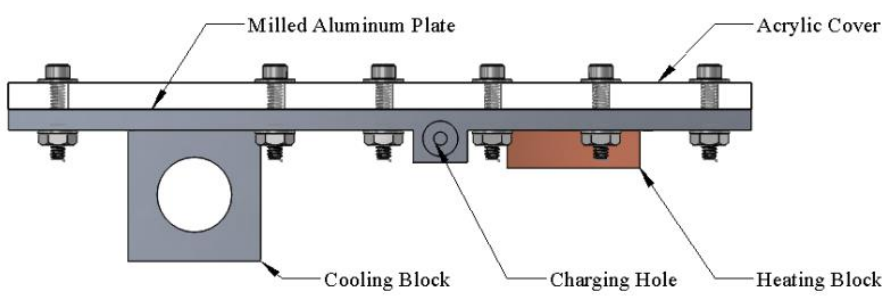

Figure 4: Side view of the apparatus displaying major components.

The frame provided a clamping force to ensure good thermal contact between the heating and cooling blocks and the PHP heat sink. Thermal grease was used at the interfaces to minimize contact resistances. The frame was designed to allow easy and accurate adjustment of the inclination angle.

Fifteen 30-gage T-type thermocouples measured the temperatures at five locations in each of the three sections (evaporator, condenser, and adiabatic) of the PHP. The thermocouples were calibrated using a reference thermometer to achieve an uncertainty of $\pm 0.2^{\circ} \mathrm{C}$. Channels $0.5 \mathrm{~mm}$ deep were milled into the back of the plate so that the thermocouples would read, with greater accuracy, the temperature of the aluminum plate near the working fluid channels. The thermocouples were offset in the direction of heat transfer in the condenser and evaporator sections to obtain better average condenser and evaporator temperatures (Fig. 4). 


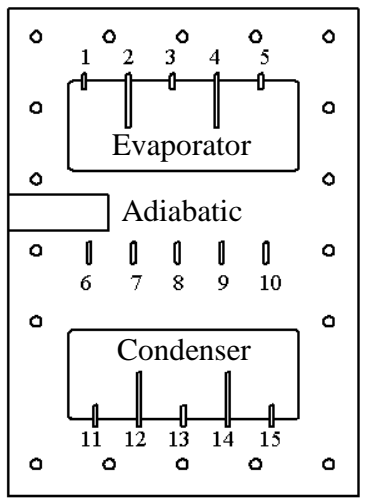

Figure 5: Thermocouple locations on the backside of the PHP.

Voltage and current transducers were used to measure the power supplied to the heaters. The transducers had uncertainties of $1 \%$ and $0.5 \%$ for current and voltage, respectively. A data acquisition system was used to record the data from the thermocouples and transducers at a rate of $1000 \mathrm{~Hz}$. Once steady state had been reached, average values were determined over a five-minute period. Steady state was determined to be reached if the standard deviation of the evaporator temperature was less than $0.5^{\circ} \mathrm{C}$ over a five-minute period.

\section{Procedure}

The PHP was evacuated prior to testing using a vacuum pump capable of achieving pressures of $2 \mathrm{~Pa}$ absolute. Then degassed, deionized water was added to the PHP until the desired fill ratio was obtained. The inclination angle was next set to the appropriate angle for the test. Depending on the condenser condition desired, a cooling bath was used to maintain the condenser temperature at $20^{\circ} \mathrm{C}$ or $30^{\circ} \mathrm{C}$. A heat input between $10 \mathrm{~W}$ and $110 \mathrm{~W}$ was supplied by the heater block. At each power input, the system was allowed to reach steady state. This process was then repeated at a tilt angle of $45^{\circ}$ above horizontal. The fill ratio for all experiments was $75 \% \pm 5 \%$. 


\section{Heat Loss Estimation}

In order to account for heat losses to the ambient, a heat loss experiment was conducted. This was accomplished by testing an uncharged (dry) PHP. As the power input was varied, the evaporator, condenser, and ambient temperature were measured. Using the evaporator and condenser temperatures and the published values for conductivity of aluminum 6061T651, the heat transfer due to conduction through the PHP was found (Eq. 2). The conduction heat transfer was subtracted from the total heat input to find the heat loss (Eq. 3). Next, a relationship between heat loss and the difference between evaporator and ambient temperature was developed (Eq. 4). This relationship was used to account for heat loss in the experiments.

$$
\begin{gathered}
Q_{\text {cond }}=\frac{\left(T_{E}-T_{C}\right)\left(A_{x S}\right)(k)}{x} \\
Q_{\text {loss }}=Q_{\text {in }}-Q_{\text {cond }} \\
Q_{\text {loss }}=.2707\left(T_{E}-T_{A}\right)-.3565
\end{gathered}
$$

\section{Data Reduction}

To determine the temperatures of the evaporator and condenser sections, an average of the five thermocouples in each section is determined (Eq. 5 and Eq. 6).

$$
\begin{gathered}
T_{E}=\frac{1}{5} \sum_{i=1,2,3,4,5} T_{\max , i} \\
T_{C}=\frac{1}{5} \sum_{i=11,12,13,14,15} T_{\min , i}
\end{gathered}
$$

The power input to the system was found from the product of the voltage and current transducers (Eq. 7).

$$
P=V I
$$

The thermal resistance was used to evaluate PHP performance. The thermal resistance was determined by taking the difference between the evaporator and condenser temperatures divided by the difference in the power inputted and the heat loss (Eq. 8). This gave the thermal resistance of the PHP system, including the contributions of both conduction through the aluminum and the heat transfer due to the oscillating PHP flow.

$$
R_{P H P}=\frac{\left(T_{E}-T_{C}\right)}{Q_{\text {in }}-Q_{\text {loss }}}
$$




\section{RESULTS}

The objective of this research was to implement a PHP successfully into a flat plate for use in electronics cooling. The enhancement due to the PHP was determined by subtracting the heat loss to the environment and heat transfer through the aluminum plate from the power input.

Some lessons were learned in the construction of the PHP heat sink prototype. In the original heat sink design, the aluminum plate was $5 \mathrm{~mm}$ thick; this resulted in a large conductive heat transfer that negatively affected the PHP's performance (as well as making it harder to determine the magnitude of the PHP-provided enhancement). It was also determined that a stronger clamping force than used initially was required to reduce thermal resistance between the PHP and the heating and cooling blocks. Finally, a good cooling block design is essential for heat removal from the condenser section of the PHP, especially at higher inputs. If the cooling block is undersized, then the PHP's power range will be severely limited.

Table 1 presents the results of the PHP performance when it is uncharged for use as a comparison to show how the PHP improves heat transfer.

Table 2 and 3 presents the steady-state performance values for all four operating conditions. The PHP provided significant heat transfer improvements over the aluminum plate alone. Uncharged, the PHP was able to transfer a maximum of 50 watts before the evaporator temperature reached a critical value $\left(90^{\circ} \mathrm{C}\right)$ that would reduce a microprocessor's performance and lifespan. When charged, the PHP was able to maintain an operational temperature for a microprocessor even with significantly larger amount of input power. This shows that if it is charged, the PHP greatly improves the heat transfer over the aluminum plate alone. Power inputs were increased until the cooling bath capacity was reached and it was no longer maintainable at the desired condenser temperature. 
Table 1: Results of operating the pulsating heat pipe uncharged (dry) for varying power input levels. The corresponding evaporator temperature is also presented.

\begin{tabular}{|c|c|c|}
\hline & Evaporator Temperature $\left({ }^{\circ} \mathrm{C}\right)$ & Thermal Resistance $(\mathrm{K} / \mathrm{W})$ \\
\hline Power $(\mathrm{W})$ & - & - \\
\hline 10 & 38.9 & 1.97 \\
20 & 53.7 & 1.97 \\
30 & 68.4 & 1.97 \\
40 & 80.9 & 1.97 \\
50 & 93.7 & 1.97 \\
\hline
\end{tabular}

Table 2: Steady-state operation of the pulsating heat pipe when it is in the vertical orientation.

\begin{tabular}{|c|l|l|l|l|}
\hline \multirow{2}{*}{} & \multicolumn{4}{|c|}{ Condenser Temperature } \\
\cline { 2 - 5 } & $20^{\circ} \mathrm{C}$ & $30^{\circ} \mathrm{C}$ & $20^{\circ} \mathrm{C}$ & $30^{\circ} \mathrm{C}$ \\
\hline Power & \multicolumn{3}{|c|}{ Evaporator Temperature } & \multicolumn{2}{|c|}{ Thermal Resistance (K/W) } \\
\hline $\mathrm{W}$ & 33.4 & 39.7 & 1.53 & 1.69 \\
\hline 10 & 41.7 & 44.6 & 1.30 & 1.05 \\
20 & 48.6 & 49.6 & 1.22 & 0.85 \\
30 & 53.0 & 55.6 & 1.01 & 0.80 \\
40 & 55.4 & 61.7 & 0.83 & 0.73 \\
50 & 55.9 & 63.8 & 0.66 & 0.66 \\
60 & 57.3 & 65.9 & 0.59 & 0.61 \\
70 & 59.7 & 70.1 & 0.54 & 0.56 \\
80 & 63.9 & 71.8 & 0.54 & 0.54 \\
90 & 68.8 & 74.7 & 0.49 & 0.53 \\
100 & \multicolumn{3}{|c|}{$\mathrm{C}$} & \\
\hline
\end{tabular}

The data is also shown in

Figure 6 to show more clearly the effects of inclination angle and condenser temperature on PHP performance. When the PHP is oriented vertically $\left(90^{\circ}\right)$ and the condenser temperatures are set to $20^{\circ} \mathrm{C}$ and $30^{\circ} \mathrm{C}$ the thermal resistances converge to nearly the same value as power is increased. Similarly, when the PHP is at a $45^{\circ}$ angle with the same 
evaporator temperatures the thermal resistances converge to a values slightly greater then recorded for the vertical inclination angle. This indicates that the thermal resistance may be more dependent on orientation than condenser temperature. This agrees with previous studies showing that thermal resistance decreases as power is increased and that the PHP performs better in the vertical orientation $[9,13,14]$.

Table 3: Steady-state operation of the pulsating heat pipe when it is at a $45^{\circ}$ orientation.

\begin{tabular}{|c|c|c|c|c|}
\hline \multirow{2}{*}{ Power } & \multicolumn{4}{|c|}{ Condenser Temperature } \\
\cline { 2 - 5 } & $20^{\circ} \mathrm{C}$ & $30^{\circ} \mathrm{C}$ & $20^{\circ} \mathrm{C}$ & $30^{\circ} \mathrm{C}$ \\
\hline $\mathrm{W}-$ & Evaporator Temperature & \multicolumn{2}{|c|}{ Thermal Resistance (K/W) } \\
\hline 10 & 34.6 & - & 1.93 & - \\
20 & 42.7 & 49.6 & 1.53 & 1.61 \\
30 & 47.9 & 60.1 & 1.13 & 1.52 \\
40 & 58.2 & 60.8 & 1.23 & 1.05 \\
50 & 62.2 & 64.2 & 1.05 & 0.87 \\
60 & 64.7 & 68.4 & 0.88 & 0.81 \\
70 & 69.2 & 71.3 & 0.83 & 0.73 \\
80 & 73.5 & 71.7 & 0.76 & 0.63 \\
90 & - & 75.2 & - & 0.59 \\
100 & - & 80.2 & - & 0.59 \\
\hline
\end{tabular}

As the heat input was increased, the thermal resistance for both condenser temperatures converged to approximately the same value. It should be noted, however, that in the intermediate power range, the thermal resistance was lowest in the vertical orientation for the $30^{\circ} \mathrm{C}$ evaporator temperature. 


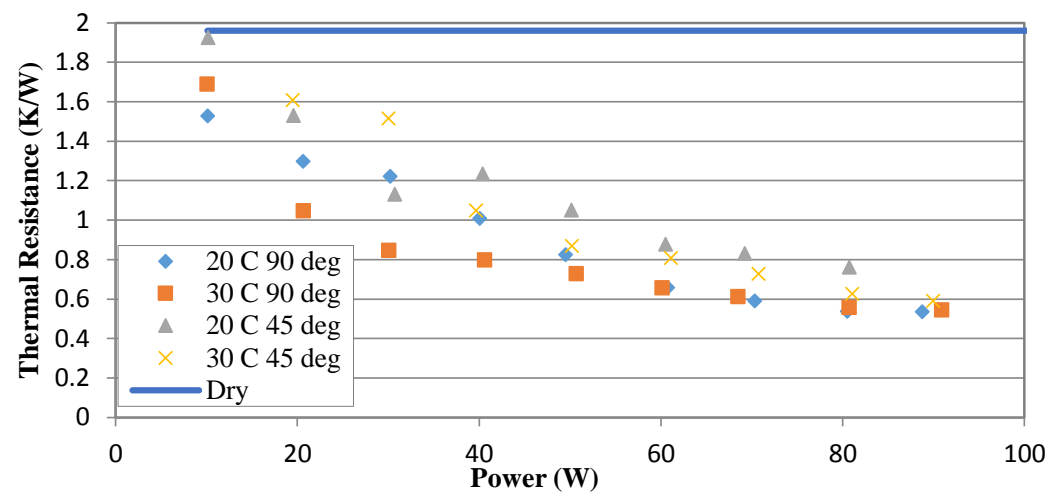

Figure 6: PHP thermal resistance performance for various power inputs, inclination angles, and condenser temperatures are all displayed in the graph above.

It can be seen in Figure 6 that when the evaporator temperature is $30^{\circ} \mathrm{C}$ and vertically oriented a lower thermal resistance is produced, it produces an evaporator temperature similar to that seen when the evaporator temperature is $20^{\circ} \mathrm{C}$ and oriented at $45^{\circ}$. The difference in performance was significant enough that the heater temperatures for the case with a $45^{\circ}$ inclination angle and $20^{\circ} \mathrm{C}$ condenser temperature were similar to those for the vertical orientation and $30^{\circ} \mathrm{C}$ condenser temperature. In a study conducted by Hansen et al., it was concluded that operating the PHP with a warmer, condenser temperature could reduce evaporator temperature and improve performance [17]. The results of this study do not definitively support this claim. In the vertical orientation the $20^{\circ} \mathrm{C}$ condenser temperature had a lower thermal resistance, but in the $45^{\circ}$ orientation the $30^{\circ} \mathrm{C}$ condenser temperature had the lower resistance. It is shown that the PHP performance is not significantly reduced by operating the condenser at a warmer temperature, indicating that performance may be relatively consistent over a wider range of condenser temperature.

It was observed that when the PHP was vertically oriented $\left(90^{\circ}\right)$ pulsations did not start until $30 \mathrm{~W}$. At this power input, pulsations were very inconsistent and temperature fluctuations in the evaporator section were large. As power was increased pulsation frequency increased, this resulted in smaller fluctuations in the evaporator. At the maximum input power, the pulsations were at such a high frequency that the evaporator temperature was nearly constant. 


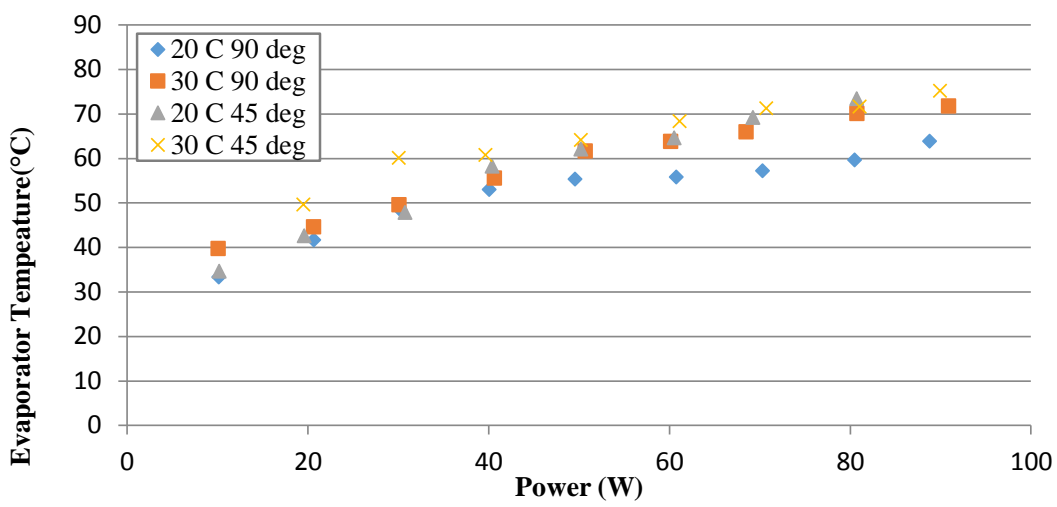

Figure 7: PHP evaporator temperature for various power inputs, inclination angles, and condenser temperatures are displayed in the graph above.

When the PHP was oriented at $45^{\circ}$ up from horizontal, results similar to the vertical orientation $\left(90^{\circ}\right)$ were observed. As power increased, pulsation frequency increased resulting in a more constant evaporator temperature. The notable difference between the two orientations is that when pulsations begin at the $45^{\circ}$ orientation, approximately 40 $50 \mathrm{~W}$, pulsations are very cyclic. Indicating that the evaporator approaches an upper threshold temperature where pulsation begins. After a short period of pulsation, thus cooling the evaporator section, a lower threshold is reached stopping the pulsations. The evaporator section again heats up until the upper threshold temperature is reached and the process is repeated.

Comparing the results found here to a similar apparatus developed by Yang et al. [9] shows that the determined thermal resistances are comparable. The comparison also shows a need for a cooling mechanism redesign to increase the range that the PHP can be operated. In the studies by Yang et al. [9], performance of PHP was studied up to approximately 450W, whereas this study was only capable of reaching a maximum of $110 \mathrm{~W}$ due to the limitations of the apparatus in removing heat from the condenser section.

\section{CONCLUSIONS}

A PHP was successfully integrated in a small-scale aluminum plate which could be used for electronic cooling applications. The PHP integration provided significant heat transfer 
enhancement compared to the aluminum plate alone. Thermal resistance values were as low as $0.49 \mathrm{~K} / \mathrm{W}$ and $0.53 \mathrm{~K} / \mathrm{W}$ when the condenser temperature was set to $20^{\circ} \mathrm{C}$ and $30^{\circ} \mathrm{C}$, respectively. When the PHP was tilted to $45^{\circ}$ above horizontal the PHP had a resistance of $0.76 \mathrm{~K} / \mathrm{W}$ and $0.59 \mathrm{~K} / \mathrm{W}$ when the condenser was set $20^{\circ} \mathrm{C}$ and $30^{\circ} \mathrm{C}$, respectively. Thermal resistance was much more dependent upon orientation then on condenser temperature. PHP performance could possibly be improved to better suit the thermal management needs of electronics through several modifications to this design. Because water was used, the channel sizing should be enlarged so the Bond number (currently 0.53) is in the middle of the acceptable range ( 0.49 to 3.39 ). This may help to induce pulsation at a lower power input. Another improvement would be to reduce the conductive heat transfer so that the heat transfer caused by the pulsation can better be determined. This could be done by reducing unnecessary material between channels or selecting a material with a low conductive value.

\section{LIMITATIONS}

It was observed that the cooling block was the limiting factor in the PHP overall heat transfer capacity. Cooling block design should be emphasized in future work to ensure the full potential of the PHP can be determined.

\section{ACKNOWLEDGEMENTS}

The author would like to thank the South Dakota Board of Regents for the funding of this project through the Competitive Research Grant Program. Special thanks given to Dr. Michna, who without his support and guidance this project would not have been possible.

\section{REFERENCES}

[1] Garimella, S. V., Fleischer, A. S., Murthy, J. Y., Keshavarzi, A., Prasher, R., Patel, C., Bhavnani, S. H., Venkatasubramanian, R., Mahajan, R., Joshi, Y., Sammakia, B., Myers, B. A., Chorosinski, L., Baelmans, M., Sathyamurthy, P. and Raad, P. E., 2008, "Thermal Challenges in Next-generation Electronic Systems," IEEE Transactions on Components and Packaging Technologies, 31(4), pp. 801-815. 
[2] H. Akachi., 1990, Structure of a Heat Pipe, U.S. Patent No. 4,921,041.

[3] Akachi, H., Polasek, F., \& Stulc, P., 1996, "Pulsating Heat Pipes," Proceedings of the 5th International Heat Pipe Symposium, Melbourne, Australia.

[4] S.M. Thompson, H.B. Ma, C. Wilson., 2011, "Investigation of a Flat-plate Oscillating Heat Pipe with Tesla-type Check Valves," Experimental Thermal and Fluid Science, 35(7), pp. 1265- 1273.

[5] Khandekar, S., 2004, “Thermo-Hydrodynamics of Closed Loop Pulsating Heat Pipes," $\mathrm{Ph}$. D. Dissertation, Institut fur Kernenergetik und Energiesysteme der Universitat Stuttgart, Stuttgart, Germany.

[6] Brent, T, Williams, A, Drolen, B., 2012, "Review of Pulsating Heat Pipe Working Fluid Selection," Journal of Thermophysics and Heat Transfer, 26(4), pp. 651-656.

[7] Faghri, A., 2012, "Review and Advances in Heat Pipe Science and Technology," Journal of Heat Transfer, 134(12), pp. 1-18

[8] Zhang, X. M., Xu, J. L. and Zhou, Z. Q., 2004, "Experimental Study of a Pulsating Heat Pipe Using FC-72, Ethanol, and Water as Working Fluids," Experimental Heat Transfer, 17(1), pp. 47-67.

[9] Yang, H. H., Khandekar, S. and Groll, M., 2008, "Operational Limit of Closed Loop Pulsating Heat Pipes," Applied Thermal Engineering, 28(1), pp. 49-59.

[10] Khandekar, S., Charoensawan, P., Groll, M. and Terdtoon, P., 2003, "Closed Loop Pulsating Heat Pipes - Part B: Visualization and Semi-empirical Modeling," Applied Thermal Engineering, 23(16), pp. 2021-2033.

[11] Yang, H. H., Khandekar, S. and Groll, M 2004. “Operational Characteristics of Flat Plate Closed Loop Pulsating Heat Pipes," Precedings of the 13th International Heat Pipe Conference, Shanghai, China.

[12] Khandekar, S., 2010, “Thermofluid Dynamic Study of Flat-Plate Closed-Loop Pulsating Heat Pipes," Nanoscale and Microscale Thermophysical Engineering, 6(4), pp. 303-317.

[13] Mameli, M., Marengo, M., and Zinna, S., 2012. "Thermal Simulation of a Pulsating Heat Pipe: Effects of Different Liquid Properties on a Simple Geometry.” Heat Transfer Engineering, 33(14), pp. 1177-1187. 
[14] Lin, Z., Wang, S., Huo J., Hu, Y., Chen, J., Zhang, W., Lee, E., 2011. "Heat Transfer Characteristics and LED Heat Sink Application of Aluminum Plate Oscillating Heat Pipes.” Applied Thermal Engineering, 31(14-15) pp. 2221-2229.

[15] Khandekar, S., and Groll, M., 2006, "Insights into the Performance Modes of Closed Loop and Pulsating Heat Pipes and Some Design Hints," Proceedings of the 18th National \& 7th ISHMT-ASME Heat and Mass Transfer Conference, Guwahati, India.

[16] S.M. Thompson, H.B. Ma, Cheng, P., 2011, “An Experimental Investigation of a Three-Dimensional Flat Plate Oscillating Heat Pipe with Staggered Channels," International Journal of Heat and Mass Transfer, 54(17-18), pp. 3951-3959.

[17] Hansen, N., VerSteeg, J., Michna, G., 2013. "Effect of Condenser Temperature on Pulsating Heat Pipe Performance." Proceedings of the 2013 ASME Heat Transfer Conference, Minneapolis, MN, USA. 